LETTERS TO THE EDITOR

If you have a burning desire to respond to a paper published in Thorax, why not make use of our "rapid response" option? Log on to our website (www.thoraxjnl.com), find the paper that interests you, and send your response via email by clicking on the "eletters" option in the box at the top right hand corner.

Providing it isn't libellous or obscene, it will be posted within seven days. You can retrieve it by clicking on "read eletters" on our homepage.

The editors will decide as before whether to also publish it in a future paper issue.

\section{Non-invasive ventilation}

We read with interest the recent paper published in Thorax by Plant et al which analysed predictors of the outcome of non-invasive ventilation (NIV) in patients with acute exacerbations of chronic obstructive pulmonary disease. Few data are available on this important question, and studies specifically designed to propose answers are either retrospective ${ }^{2}$ or have been performed in a small sample of patients. ${ }^{3}$ We recently published the results of a trial $l^{4}$ using a design similar to that of Plant et al. Our findings indicated that the greatest predictive power lies in variables reflecting the evolution of arterial blood gases (particularly $\mathrm{pH}$ ) after a brief ( 1 hour) initial trial period of NIV. Our multivariate predictive model had an adequate power of discrimination, correctly classifying more than $95 \%$ of the patients with a sensitivity of $97 \%$ and a specificity of $90 \%$ in a subsequently analysed sample of new patients. Our model therefore performed quite differently from that of Plant et al which had poor discriminant value even though they studied a greater number of patients.

The explanation for the differences between our findings and those of Plant et al may arise from the fact that they used data from a previous study that had not been designed to predic the result of NIV. In fact, Plant et al did not analyse all possible variables. In particular, they did not look at those which we found to be of great predictive value-namely, the evolution of the arterial gases after a short session of ventilation. Instead, they chose to analyse the arterial blood gases after 4 hours of ventilation. From a clinical standpoint, 4 hours seems to be too long if the object is to detect a failure of NIV in order to choose another therapeutic option (invasive ventilation). It would have been interesting to calculate the power of prediction of our previously published model ${ }^{4}$ had it been applied to the large sample of patients analysed by Plant et al.

Finally, as the model they proposed was not validated in a subsequent study with a new sample of patients, the clinical usefulness of the predictors is poor, as noted by the authors.

A Antón, R Güell, J Tárrega, J Sanchis Department of Respiratory Medicine, Hospital de la Santa Creu I Sant Pau, 08025 Barcelona, Spain panton@hsp.santpau.es

\section{References}

1 Plant $\mathbf{P}$, Owen J, Elliot $M$, et al. Non-invasive ventilation in acute exacerbations of chronic obstructive pulmonary disease: long term survival and predictors of in-hospital outcome. Thorax 2001:56:708-12.

2 Ambrosino N, Foglio K, Rubini F, et al. Non invasive mechanical ventilation in acute respiratory disease due to chronic obstructive pulmonary disease: correlates for success. Thorax 1995:50:755-7.

3 Soo Ho GV, Santiago S, Williams A, et al. Nasal mechanical ventilation for hypercapnic respiratory failure in chronic obstructive pulmonary disease: determinants of success and failure. Crit Care Med 1994:22:1253-61.

4 Antón A, Güell R, Gómez J, et al. Predicting the result of non invasive ventilation in sever acute exacerbations of patients with chronic airflow limitation. Chest 2000;1 17:828-33.

5 Plant PK, Owen JL, Elliott MW. Early use of non invasive ventilation for acute exacerbations of chronic obstructive pulmonary disease on general respiratory wards: a multicenter randomised controlled trial Lancet 2000 $355: 1931-5$.

\section{Non-invasive ventilation}

Non-invasive ventilation (NIV) has been shown to be of benefit in the treatment of decompensated respiratory acidosis due to an exacerbation of chronic obstructive pulmonary disease (COPD) ${ }^{1-3}$ The reduction in the need for intubation and in mortality offered by this treatment make it at least a useful initial therapy in this situation, and in some cases represents the only option available if the patient is deemed unsuitable for invasive ventilation. Plant et $a l^{4}$ specify ward based NIV in their paper, yet there is no reason why NIV could not be initiated in the emergency department, provided that the equipment is available and the nursing and medical staff are given the necessary training.

NIV has previously been assessed in this role and found to be of use as an initial treatment, with the option of intubation should treatment fail. ${ }^{5}$ Plant et $a l^{4}$ concur with previous studies that the most important initial data predicting the need for intubation and mortality are the degree of acidosis and level of hypercapnia..$^{6-8}$ It seems reasonable to assume that the earlier NIV is commenced, provided it is used appropriately, the better the outcome will be. I therefore feel that NIV should be routinely available in the emergency department in order to offer the best initial treatment at the earliest opportunity. Since intubation may well be needed should an initial trial of NIV fail, ICU staff should always be involved at an early stage with frequent reassessment of progress being part of a strict protocol of care.

E F Nash

Department of Respiratory Medicine, Bristol Royal Infirmary, Bristol, UK; ednash2000@hotmail.com

\section{References}

1 Brochard L, Mancebo J, Wysocki M, et al. Noninvasive ventilation for acute exacerbations of chronic obstructive pulmonary disease. N Engl J Med 1995;333:817-22.

2 Kramer N, Meyer TJ, Meharg J, et al. Randomized, prospective trial of noninvasive positive pressure ventilation in acute respiratory failure. Am J Respir Crit Care Med 1995; 151:1799-806.

3 Plant PK, Owen JL, Elliott MW. Early use of non-invasive ventilation for acute exacerbations of chronic obstructive pulmonary disease on general respiratory wards: a multicentre randomized controlled trial. Lancet 2000:355:1931-5.

4 Plant PK, Owen JL, Elliott MW. Non-invasive ventilation in acute exacerbations of chronic obstructive pulmonary disease: long term survival and predictors of in-hospital outcome. Thorax 2001:56:708-12.

5 Poponick JM, Renston JR, Bennett RP, et al. Use of ventilatory support system (BiPAP) for acute respiratory failure in the emergency department. Chest 1999;116:166-71.

6 Plant PK, Owen JL, Elliott MW. One-year period prevalence study of respiratory acidosis in acute exacerbations of COPD implications for the provision of non-invasive ventilation and oxygen administration. Thorax 2000;55:550-4.

7 Jeffrey AA, Warren PM, Flenley DC. Acute hypercapnic respiratory failure in patients with chronic obstructive lung disease: risk factors and use of guidelines for management Thorax 1992:47:34-40.

8 Warren PM, Flenley DC, Millar JS, et al Respiratory failure revisited: acute exacerbations of chronic bronchitis between 1961-68 and 1970-76. Lancet 1980;i:467-71.

\section{Decision analysis in NSCLC}

The paper by Dowie and Wildman ${ }^{1}$ exploring the decision analysis for surgically high risk patients with stage Ia non-small cell lung cancer (NSCLC) was interesting. However, I have reservations about the figures used to inform the decision tree.

There has never been a randomised trial comparing surgery with radical radiotherapy for these patients and the authors have taken 5 year survival figures for quite different groups of patients. The surgical survival figures come from a very large series of patients of all ages and levels of fitness, ${ }^{2}$ while the radical radiotherapy figures come from one relatively small retrospective series of patients who were considered unfit for (or refused) surgery. ${ }^{3}$ These patients have, for reasons of age and co-morbidity, a lower background probability of 5 year survival. The Cochrane Review on this topic ${ }^{4}$ identified 26 studies, including over 2000 patients. For patients with Tl tumours from six studies, 5 year survival ranged from $29 \%$ to $37 \%$, but there was a high rate of intercurrent deaths (median $25 \%$ ). So, in the model, either the 5 year survival probability for surgery needs to be adjusted down or that for radical radiotherapy adjusted up to allow for the different case mix

Also, we have no evidence on the natural history of untreated stage Ia disease. The probability of 5 year survival without treatment of $1 \%$ that is used in the model may be unduly low because it is the figure generally quoted for patients with advanced disease at presentation treated palliatively

Why are the utilities for survival 10 points lower after radical radiotherapy than after surgery? A patient who is alive at 5 years with a given level of disability should express the same utility whatever the original treatment. The utility after surgery could, in fact, be lower because some patients are troubled by post-thoracotomy chest wall pain. 
Like Treasure, ${ }^{5}$ I have the feeling that this model was derived from a theoretical study of the literature without adequate discussion with clinicians. It is, however, a start. I would be happy to cooperate on a more clinically based further exploration of the topic.

F Macbeth Velindre Hospital, Cardiff CF14 2TL, UK; fergus.macbeth@velindre-tr.wales.nhs.uk

\section{References}

1 Dowie J, Wildman N. Choosing the surgical mortality threshold for high risk patients with la non-small cell lung cancer: insights from decision analysis. Thorax 2002;57:7-10.

2 Mountain C. Revisions in the international system for staging lung cancer. Chest 1997;111:1710-7.

3 Gauden S, Ramsay J, Tripcony L. The curative treatment by radiotherapy alone in stage I non-small cell lung cancer of the lung. Chest 1995; 108: 1278-82.

4 Rowell N, Williams C. Radical radiotherapy for stage I/II non-small cell lung cancer in patients not sufficiently fit for or declining surgery (medically inoperable) (Cochrane Review) In: The Cochrane Library. Issue 4

Oxford: Update Software, 2001.

5 Treasure T. Whose lung is it anyway? Thorax 2002;57:3-4.

\section{Authors' reply}

We are grateful for the specialist input of Dr Macbeth who uses his expertise to contribute to the refinement of the probabilities and utilities in the decision tree. It was clearly not our intention to provide a definitive tree, simply an illustrative one which would demonstrate the potential of decision trees in integrating the best evidence with individual patient preference in a coherent and transparent way. But we were able to use this tree to confirm that the surgical mortality threshold for an individual patient should be determined by their expected mortality (and health related quality of life) under the alternative options, rather than by considering the surgical consequences alone.

The study by Gauden et al ${ }^{1}$ was selected to provide a point estimate of the 5 year survival possible following radiotherapy (range of 5 year survival in the Cochrane review $29-37 \%$, Gauden study 5 year survival $32 \%$ ). The Cochrane review highlights the fact that survival following radiotherapy is influenced by patients' performance status, presence or absence of weight loss, and tumour size. The tree provides a structure to allow this complexity to be explicitly taken into account. We see decision trees allowing experts in the various disciplines involved in cancer care to operationalise textual guidelines and evidence for multidisciplinary decision making in a transparent and analytically coherent way. Consensus techniques would be required to identify the important patient archetypes, the best evidence applying to these archetypes, and the implications of the archetypes for each of the candidate treatment modalities. Macbeth illustrates the necessity of this process by suggesting the need to alter the 5 year survival probability in the light of case mix. A similar consensus process (taking patient characteristics into account) could be used to refine the probability of 5 year survival without treatment.

As far as utilities are concerned, these are best elicited directly from patients using techniques that also take account of attitudes to risk. In the tree in the paper the utility of 5 year surgical survivors is set at 100 in patients with only mild shortness of breath, but at 70 in 5 year surgical survivors with severe shortness of breath. In order to keep the illustrative tree relatively simple, 5 year survivors of radiotherapy include all levels of dyspnoea and the utility chosen lies between the two groups of surgical survivors to take account of this.

Both Macbeth and Treasure ${ }^{3}$ are absolutely correct to observe that the paper represents a largely theoretical demonstration of the potential of decision analysis, though that does not mean it has not already yielded some important insights. We agree that a substantive decision analysis requires extensive discussion and collaboration with both clinicians and patients, and we would welcome an opportunity to take this work forward in such a cooperative environment. In our experience clinicians-and funding bodies-vary enormously in their assessment of the value of analysis based decision technologies, but it is reassuring to see that there is increasing recognition of their future potential.

J Dowie, $M$ Wildman

Public Health and Policy Department, London School of Hygiene and Tropical Medicine, London WC1E 7HT, UK; jack.dowie@lshtm.ac.uk

\section{References}

1 Gauden S, Ramsay J, Tripcony L. The curative treatment by radiotherapy alone in stage I non-small cell carcinoma of the lung. Chest 1995; 108: 1278-82.

2 Rowell NP, Williams CJ. Radical radiotherapy for stage $\mathrm{I} / \mathrm{II}$ non-small cell lung cancer in patients not sufficiently fit for or declining surgery (medically inoperable). The Cochrane Library. Issue 1. Oxford: Update Software, 2002.

3 Treasure T. Whose lung is it anyway? Thorax 2002;57:3-4. 